\title{
Produção de mudas por estaquia de duas espécies de guaco
}

\author{
Narumi P. Lima ${ }^{1}$; Luiz Antonio Biasi ${ }^{1}$; Flávio Zanette ${ }^{1}$; Tomoe Nakashima ${ }^{2}$ \\ ${ }^{1}$ UFPR, Depto. Fitotecnia e Fitossanitarismo, C. Postal 19061, 81.531-990 Curitiba-PR; ${ }^{2}$ UFPR, Depto. Farmácia, R. Lotário Meissner, \\ 3400, Jardim Botânico, 80.210-170 Curitiba-PR; E-mail: labiasi@agrarias.ufpr.br
}

\section{RESUMO}

Visando a obtenção de subsídios técnicos à produção em escala comercial, avaliou-se o substrato e o sistema de irrigação mais indicados para a estaquia do guaco. Também foi observado o desenvolvimento a campo das duas espécies, Mikania glomerata e Mikania laevigata. No experimento de estaquia, foram avaliados os substratos (casca de arroz carbonizada, areia e solo), e os sistemas de irrigação (nebulização ou rega manual), no delineamento experimental de blocos casualizados, com quatro repetições e vinte estacas por parcela. As estacas utilizadas tinham $12 \mathrm{~cm}$ de comprimento, 0,7 a $1,0 \mathrm{~cm}$ de diâmetro e foram retiradas da parte mediana dos ramos. A avaliação foi feita 60 dias após a instalação do experimento. Constatou-se que o enraizamento foi melhor no substrato casca de arroz carbonizada, sendo obtidas $94,38 \%$ de estacas enraizadas para $M$. laevigata e $88,12 \%$ para $M$. glomerata. O sistema de irrigação não influenciou a porcentagem de enraizamento, mas foi observado maior volume e massa seca de raízes sob rega manual. Na observação sobre o desenvolvimento a campo das duas espécies, constatou-se que $M$. laevigata apresentou maior tolerância ao frio que $M$. glomerata. $\mathrm{O}$ rendimento de M. laevigata, avaliado 17 meses após o plantio, resultou em $501,5 \mathrm{~g}$ de matéria seca de folhas/planta. Com base nestes experimentos, concluiu-se que a estaquia do guaco pode ser realizada em casca de arroz carbonizada, sob rega manual.

Palavras-chave: Mikania glomerata, Mikania laevigata, propagação vegetativa, planta medicinal, substrato.

\section{ABSTRACT}

\section{Nursery plants production of two "guaco" species}

Technical subsidies for the commercial production scale of "guaco", were evaluated, determining the better substratum and irrigation systems for rooting cuttings of "guaco". The development of the two species (Mikania glomerata and Mikania laevigata) was observed in the field. Different substrata in the cuttings experiment were evaluted (carbonized rice husk, sand and soil), under two irrigation systems (intermittent mist or manual irrigation). The experimental design was a randomized complete block, with four replications and twenty cuttings per plot. Cuttings were $12 \mathrm{~cm}$ long and $0.7-10 \mathrm{~cm}$ in diameter, taken from the medium part of the branches. Data were obtained 60 days after the installation of the experiments. The best rooting occurred in carbonized rice husk, with $94,38 \%$ of rooting cuttings for $M$. laevigata and $88,12 \%$ for $M$. glomerata. The irrigation systems did not affect the rooting, but the greatest volume and dry matter of roots were observed with manual irrigation. In the comparison of yield between the two species, $M$. laevigata presented larger tolerance to frost than $M$. glomerata. Mean yield of $M$. laevigata, evaluated 17 months after planting date, resulted in $501,5 \mathrm{~g}$ of dry matter/plant. We concluded that the propagation through cuttings can be done with carbonized rice husk, under manual irrigation.

Keywords: Mikania glomerata, Mikania laevigata, vegetative propagation, medicinal plant, substratum.

\section{(Recebido para publicação em 23 de agosto de 2001 e aceito em 20 de dezembro de 2002)}

$\mathrm{O}$ gênero Mikania tem cerca de 415 espécies distribuídas principalmente nas Américas do Sul e Central (Ritter et al., 1992). No Brasil, o gênero, com 171 espécies, ocorre de norte a sul, tendo sua principal área de dispersão nos estados de Minas Gerais, Rio de Janeiro e São Paulo (Barroso, 1958; Oliveira, 1983). No estado do Paraná, foram descritas 69 espécies (Angely, 1965).

As principais espécies medicinais pertencentes ao gênero Mikania encontram-se na secção Globosae Robinson. Duas das espécies brasileiras dessa secção são Mikania glomerata Sprengel e Mikania laevigata Schultz Bip. ex Baker (Barroso, 1958). A espécie mais utilizada para fins medicinais é Mikania glomerata, que assim como Mikania hirsutissima DC, foi oficializada como fitofármaco na primeira edição da
Pharmacopeia dos Estados Unidos do Brasil (Silva, 1929). A M. glomerata é a espécie mais estudada e, dela existem muitos dados sobre a composição química e seu princípio ativo. São componentes do extrato hexânico da planta: cumarinas, estigmasterol e um éster alifático insaturado (Oliveira et al., 1984). Lucas (1942) já havia detectado a presença do glicósido cumarina no vegetal e substâncias resinosas, que podem estar relacionadas com a ação expectorante do vegetal.

Para a estaquia do guaco, devem ser utilizados ramos com 15 a $20 \mathrm{~cm}$, tratados com fungicidas e ter um par de folhas cortadas ao meio. O plantio do guaco deve ser realizado em covas adubadas com esterco de curral e a distância entre plantas deve ser de $2 \mathrm{~m}$. Para o cultivo é necessário tutorar a planta em espaldeiras, realizando amarrações pe- riódicas dos ramos nos arames no sentido anti-horário, já que o guaco é uma planta levógira. A colheita das folhas pode ser realizada após os 16 meses do plantio, sendo possível colher entre duas e quatro vezes por ano, sempre deixando pelo menos $30 \%$ dos ramos com folhas na planta para permitir a sua recuperação vegetativa. A produtividade é de aproximadamente $8 \mathrm{~kg}$ de matéria fresca por planta, ocorrendo uma quebra de $75 \%$ após a secagem (Magalhães, 1997; Montanari Jr., 1999).

Na busca de subsídios técnicos à produção em escala comercial, o objetivo deste trabalho foi encontrar o substrato e sistema de irrigação mais indicados para a propagação via estaquia de duas espécies de guaco. Também foram realizadas algumas observações sobre o desenvolvimento de Mikania laevigata e Mikania glomerata a campo. 
Tabela 1. Efeito do substrato e do sistema de irrigação na mortalidade (\%) e retenção foliar (\%) de estacas de Mikania glomerata. Curitiba, UFPR, 1999.

\begin{tabular}{lccc}
\hline \multirow{2}{*}{ Sistema de irrigação } & \multicolumn{2}{c}{ Substrato } \\
\cline { 2 - 4 } & $\begin{array}{c}\text { Casca de arroz } \\
\text { carbonizada }\end{array}$ & Areia & Solo \\
\cline { 2 - 4 } Rega diária & $0,00 \mathrm{bB}^{1}$ & Mortalidade (\%) \\
Nebulização & $18,75 \mathrm{aA}$ & $3,75 \mathrm{aB}$ & $53,75 \mathrm{aA}$ \\
\hline C.V. & \multicolumn{3}{c}{ Retenção foliar (\%) } \\
\hline & & $96,25 \mathrm{aA}$ & $17,50 \mathrm{bA}$ \\
\hline Rega diária & $99,38 \mathrm{aA}^{1}$ & $96,25 \mathrm{aA}$ & $93,75 \mathrm{aA}$ \\
Nebulização & $86,25 \mathrm{bB}$ & $3,3 \%$ & $91,25 \mathrm{aAB}$ \\
\hline C.V. & & 3
\end{tabular}

${ }^{1}$ Médias seguidas da mesma letra, minúscula nas colunas e maiúscula nas linhas, não diferem significativamente pelos Teste F e Tukey, respectivamente, a $5 \%$ de probabilidade.

\section{MATERIAL E MÉTODOS}

Os experimentos de estaquia foram conduzidos na casa de vegetação da UFPR, em Curitiba (PR). As observações no campo das duas espécies foram realizadas na Fazenda Experimental do Canguiri da UFPR, localizada no município de Pinhais (PR).

Foram coletados ramos com flores e estacas de plantas de Mikania laevigata e Mikania glomerata que estavam se desenvolvendo em condições naturais na Fazenda Experimental do Canguiri. As exsicatas preparadas das duas espécies foram incorporadas ao herbário do Departamento de Botânica da UFPR com os números 39384 e 39385; ao Herbário do Departamento de Botânica da UFRGS sob os números ICN 116507 e ICN 116508 e ao Herbário da UNICAMP sob os números UEC 110400 e UEC 110401, respectivamente.

As estacas foram retiradas da parte mediana dos ramos das plantas, entre o terceiro e o nono nó, tendo o diâmetro variando de 0,7 a $1,0 \mathrm{~cm}$, comprimento de aproximadamente $12,0 \mathrm{~cm}$ e apenas um nó na parte superior da estaca, no qual foi deixado um par de folhas inteiras.

Os tratamentos foram compostos de dois sistemas de irrigação (câmara de nebulização, com irrigação intermitente durante dois minutos, e intervalo de rega de trinta minutos, e rega manual diária com mangueira) e três tipos de substrato (casca de arroz carbonizada, areia e solo). $\mathrm{O}$ experimento foi reali- zado em parcelas subdivididas, com delineamento em blocos casualizados, com quatro repetições e vinte estacas por parcela, totalizando 960 estacas. Os dois sistemas de irrigação testados encontravam-se dentro da mesma casa de vegetação. A instalação se deu em 09/03/ 1999. Após 60 dias foram avaliadas as características porcentagem de enraizamento, de mortalidade, de brotação e de retenção foliar das estacas; comprimento das brotações $(\mathrm{cm})$; volume de raízes $(\mathrm{mL})$ e massa seca $(\mathrm{g})$ de raízes emitidas por estaca. O comprimento das brotações foi obtido pela determinação com régua do crescimento dos brotos novos originados das gemas da estaca e o volume de raízes, pelo deslocamento de água dentro de uma proveta graduada.

A análise física dos substratos foi realizada segundo o procedimento descrito por Fretz et al. (1979).

O plantio a campo das duas espécies foi realizado em novembro/98, em covas espaçadas de $1,0 \mathrm{~m}$ na linha e $2,0 \mathrm{~m}$ nas entrelinhas, utilizando estacas semilenhosas com 60 dias após o enraizamento em casca de arroz carbonizada, sendo levadas diretamente para o campo. A condução das mudas se deu em espaldeira de três fios, com $0,8 \mathrm{~m}$, $1,2 \mathrm{~m} \mathrm{e} 1,6 \mathrm{~m}$ de altura, e com $8,0 \mathrm{~m}$ de comprimento, com três repetições e três plantas por parcela. A área foi mantida limpa de plantas invasoras por meio de capinas. Não foram realizadas adubações ou irrigação. Em abril/00 foi avaliada a produção de massa seca de folhas (g/planta).

\section{RESULTADOS E DISCUSSÃO}

Para a espécie $M$. glomerata, houve interação significativa entre o tipo de substrato e sistema de irrigação para as características mortalidade de estacas e retenção foliar (Tabela 1). Para todas as outras características avaliadas não houve diferença significativa entre os tratamentos. No caso de M. laevigata, houve interação entre tipos de substrato e sistemas de irrigação para todas as características (Tabela 2 ), exceto porcentagem de enraizamento (Tabela 3). De uma forma geral as duas espécies enraizaram com facilidade, apresentando uma média de $81,4 \%$ para $M$. laevigata e 73,9\% para $M$. glomerata.

O sistema de irrigação não influenciou a porcentagem de enraizamento das duas espécies; apenas foi encontrada maior porcentagem de enraizamento na casca de arroz carbonizada para $M$. laevigata (Tabela 3). Para ambas espécies o índice mais alto de mortalidade foi observado com o substrato solo nos dois sistemas de irrigação. A retenção foliar foi alta em todo o experimento (Tabelas 1 e 2), o que deve ter contribuído para a obtenção dos elevados índices de enraizamento (Hartmann et al., 1990). A importância da folha na formação das raízes adventícias fica evidente quando se observa que, para $M$. laevigata, a menor taxa de enraizamento foi obtida no substrato solo (Tabela 3), onde também foram obtidas menores taxas de retenção foliar (Tabela 2).

O comprimento médio das brotações, para M. laevigata (Tabela 2), 
Tabela 2. Efeito do substrato e do sistema de irrigação na brotação, mortalidade, retenção foliar, comprimento das brotações, volume e massa seca de raízes por estaca de Mikania laevigata. Curitiba, UFPR, 1999.

\begin{tabular}{|c|c|c|c|}
\hline \multirow[b]{2}{*}{ Sistema de irrigação } & \multicolumn{3}{|c|}{ Substrato } \\
\hline & $\begin{array}{c}\text { Casca de arroz } \\
\text { carbonizada }\end{array}$ & Areia & Solo \\
\hline & \multicolumn{3}{|c|}{ Brotação (\%) } \\
\hline Rega diária & $31,25 \mathrm{aA}^{1}$ & $30,0 \mathrm{Aa}$ & 37,50 aA \\
\hline Nebulização & $28,75 \mathrm{aA}$ & $2,50 \mathrm{bB}$ & $18,75 \mathrm{bA}$ \\
\hline \multirow[t]{2}{*}{ C.V. } & & $28,6 \%$ & \\
\hline & \multicolumn{3}{|c|}{ Mortalidade (\%) } \\
\hline Rega diária & $3,75 \mathrm{aB}^{1}$ & $12,50 \mathrm{aB}$ & $37,50 \mathrm{aA}$ \\
\hline Nebulização & $7,50 \mathrm{aB}$ & $3,75 \mathrm{bB}$ & $18,75 \mathrm{bA}$ \\
\hline \multirow[t]{2}{*}{ C.V. } & & $36,3 \%$ & \\
\hline & \multicolumn{3}{|c|}{ Retenção foliar (\%) } \\
\hline Rega diária & $95,63 a^{1}$ & $91,88 \mathrm{aA}$ & 88,75 aA \\
\hline Nebulização & 83,13 aA & 94,38 aA & 56,88 bB \\
\hline \multirow[t]{2}{*}{ C.V. } & & $11,2 \%$ & \\
\hline & \multicolumn{3}{|c|}{ Comprimento de brotações $(\mathrm{cm})$} \\
\hline Rega diária & $2,856 \mathrm{aB}^{1}$ & $3,087 \mathrm{aB}$ & $5,334 \mathrm{aA}$ \\
\hline Nebulização & $1,554 \mathrm{bA}$ & $0,206 \mathrm{bB}$ & $1,100 \mathrm{bAB}$ \\
\hline \multirow[t]{2}{*}{ C.V. } & & $22,5 \%$ & \\
\hline & \multicolumn{3}{|c|}{ Volume de raízes $(\mathrm{mL})$} \\
\hline Rega diária & $32,875 \mathrm{aA}^{1}$ & $13,125 \mathrm{aC}$ & $21,500 \mathrm{aB}$ \\
\hline Nebulização & $24,500 \mathrm{bA}$ & $5,375 \mathrm{bB}$ & $2,775 \mathrm{bB}$ \\
\hline \multirow[t]{2}{*}{ C.V. } & & $12,4 \%$ & \\
\hline & \multicolumn{3}{|c|}{ Massa seca de raízes $(\mathrm{g})$} \\
\hline Rega diária & $4,670 \mathrm{aA}^{1}$ & $1,785 \mathrm{aB}$ & $2,656 \mathrm{aB}$ \\
\hline Nebulização & $2,346 \mathrm{bA}$ & $1,210 \mathrm{aAB}$ & $0,425 \mathrm{bB}$ \\
\hline
\end{tabular}

${ }^{1}$ Médias seguidas da mesma letra, minúscula nas colunas e maiúscula nas linhas, não diferem significativamente pelos Teste $\mathrm{F}$ e Tukey, respectivamente, a 5\% de probabilidade.

foi maior no substrato solo com rega diária e, para $M$. glomerata, não houve diferença entre os tratamentos. O volume e a massa seca de raízes emitidas por estaca foi maior em substrato casca de arroz carbonizada para $M$. laevigata (Tabela 2). Biasi \& De Bona (2000) obtiveram resultados semelhantes na estaquia de carqueja (Baccharis trimera), onde o volume de raízes por estaca, em casca de arroz carbonizada, foi praticamente o dobro dos demais substratos. Para M. laevigata, o sistema de irrigação também influenciou o desenvolvimento das raízes, sendo encontrados os maiores valores com a rega diária (Tabela 2). Na produção de mudas de amor-perfeito e tomate, Kämpf (1993) observou melhor desenvolvimento das mudas num substrato conten- do casca de arroz carbonizada. $\mathrm{Na}$ estaquia herbácea e semilenhosa de alfavaca-cravo em ambiente com nebulização, também foi observado comportamento semelhante quanto à massa seca de raízes em diversos substratos (Ehlert et al., 2000). Por outro lado, considerando outras características analisadas, os autores recomendaram a mistura de arisco mais esterco (20\%), húmus $(40 \%)$ e vermiculita (40\%) como substrato para estacas da posição mediana.

De modo geral, tanto para $M$. glomerata quanto para M. laevigata, observou-se melhor comportamento no substrato casca de arroz com rega manual diária. Isso pode ter ocorrido devido ao fato desse substrato possuir, em relação aos demais estudados, maior capacidade de retenção de água $(34,8 \%)$, maior espaço poroso $(40,7 \%)$ e menor densidade (243 g.L. L $^{-1}$ ), o que permitiria bom desenvolvimento das raízes, mesmo sem nebulização.

Por ter menor capacidade de retenção de água $(27,7 \%)$ e menor espaço poroso $(19,8 \%)$, o solo não foi um substrato adequado para as espécies em questão. Schmitz et al. (1999), avaliando as características físicas de diversos substratos, comentaram que materiais minerais, como solo e areia, possuem excessiva densidade e reduzida porosidade, sendo deficientes em aeração. Isso foi constado na análise física dos substratos, onde a densidade do solo foi 1.061 g.L $\mathrm{L}^{-1}$ e da areia foi 1.368 
g.L $\mathrm{L}^{-1}$, o que proporcionou um reduzido espaço poroso total, de $47,7 \%$ e $32,5 \%$, respectivamente.

De acordo com os resultados encontrados, o guaco parece ser uma planta mais exigente em aeração do que umidade no substrato para a estaquia. Isso porque sob nebulização, em comparação com a irrigação diária, devido à elevada freqüência de rega, a aeração do substrato, provavelmente, estava reduzida devido à ocupação dos poros pela água de irrigação. Esse comportamento é diferenciado e característico para cada espécie, pois para Limonium latifolium, as mudas cresceram melhor em substratos com maior retenção de água (Schneider \& Kämpf, 1999).

Na observação sobre o desenvolvimento a campo, verificou-se que o crescimento vegetativo inicial foi semelhante visualmente entre as duas espécies avaliadas. Entretanto, a ocorrência de uma geada $\left(-2,2^{\circ} \mathrm{C}\right)$ durante o inverno (Simepar, 1999) ocasionou a morte de todas as plantas da espécie $M$. glomerata. Segundo Correa Júnior et al. (1994), essa espécie é influenciada pela geada em campo aberto. Por outro lado, as plantas de $M$. laevigata não apresentaram sintoma visual de dano, continuando o seu desenvolvimento vegetativo e reprodutivo, pois já estavam no início da formação das inflorescências. Apesar da maior tolerância ao frio essa espécie não pode ser considerada resistente à geada, pois no inverno do ano 2000 , com a ocorrência de várias geadas fortes, atingindo a temperatura mínima de $-3,5^{\circ} \mathrm{C}$ (Simepar, 2000), todas as plantas de M. laevigata também morreram. A maior tolerância ao frio pode ser explicada pelo fato de a espécie ocorrer de forma mais abundante do que $M$. glomerata no Rio Grande do Sul (Simões et al., 1995).

A colheita de M. laevigata foi realizada após 17 meses do plantio, sendo obtida uma média de 501,5 g de matéria seca de folhas por planta. Com o espaçamento utilizado de $2 \times 1 \mathrm{~m}$, podese estimar a obtenção de $2,5 \mathrm{t} / \mathrm{ha}$ de matéria seca de guaco. Este resultado está bastante próximo do relatado por Correa Júnior et al. (1994), que citam o rendimento de 1,5-2,5 t/ha de planta seca; por Castro \& Chemale (1995), que citam o rendimento de 1,6-2,0 t/ha ( 8 a $10 \mathrm{t} / \mathrm{ha}$ de folhas e ramos, com redução

Tabela 3. Efeito do substrato e do sistema de irrigação no enraizamento de estacas de Mikania laevigata. Curitiba, UFPR, 1999.

\begin{tabular}{lc}
\hline \multicolumn{1}{c}{ Substrato } & Enraizamento (\%) \\
\hline Casca de arroz carbonizada & $94,38 \mathrm{a}^{1}$ \\
Areia & $85,00 \mathrm{ab}$ \\
Solo & $65,00 \mathrm{~b}$ \\
\hline Sistema de irrigação & \\
\hline Rega diária & $80,00 \mathrm{a}$ \\
Nebulização & $82,92 \mathrm{a}$ \\
\hline C.V. & $31,7 \%$ \\
\hline
\end{tabular}

${ }^{\mathrm{I}}$ Médias seguidas de mesma letra não diferem significativamente pelo teste de Tukey, a 5\% de probabilidade.

de $80 \%$ após a secagem) e por Magalhães (1997), que cita a obtenção de 1,95 t/ha de folhas e ramos secos após 16 meses, no primeiro corte. Montanari Jr. (1999) cita que a primeira colheita pode ser feita aos 16 meses após o plantio, e o rendimento pode chegar a $8 \mathrm{~kg} /$ planta de massa fresca, havendo redução de $75 \%$ da massa após a secagem.

\section{AGRADECIMENTO}

Os autores agradecem aos professores Olavo de Araújo Guimarães (UFPR); Mara Ritter (UFRGS) e Marta Dias de Moraes (UNICAMP), pelo valioso trabalho de identificação das espécies estudadas.

\section{LITERATURA CITADA}

ANGELY, J. Flora analítica do Paraná. São Paulo: Phyton, 1965. 671 p.

BARROSO, G.M. Mikaniae do Brasil. Revista do Arquivo do Jardim Botânico do Rio de Janeiro, Rio de Janeiro, v. 16, p. 239-333, 1958.

BIASI, L.A.; DE BONA, C.M. Propagação de carqueja (Baccharis trimera (Less.) A.P. de Candolle por meio de estaquia. Revista Brasileira de Plantas Medicinais, Botucatu, v. 2, n. 2, p. 37-43, 2000.

CASTRO, L.O.; CHEMALE, V.M. Plantas medicinais, condimentares e aromáticas - descrição e cultivo. Guaíba: Agropecuária, 1995. 196 p. CORREA JUNIOR, C.; MING, L.C.; SCHEFFER, M.C. Cultivo de plantas medicinais, condimentares e aromáticas. Botucatu: UNESP, 1994. 162 p.

EHLERT, P.A.D.; LUZ, J.M.Q.; INNECCO, R. Avaliação de substratos e tipos de estacas para propagação vegetativa de alfavaca-cravo. Horticultura Brasileira, Brasília, v. 18, suplemento, p. 951-953, 2000.

FRETZ, T.A.; READ, P.E.; PEELE, M.C. Plant propagation laboratory manual. Minneapolis: Bengess Publishiny Company, 1979. 317 p.

HARTMANN, H.T.; KESTER, D.E.; DAVIES JUNIOR, F.T. Plant propagation: principles and practices. 5 ed. Englewood Cliffs: Prentice Hall, 1990. 647 p.
KÄMPF, A.N. Substratos hortícolas: turfa e casca de arroz. Lavoura Arrozeira, Porto Alegre, v. 46, n. 409, p. 12-13, 1993.

LUCAS, V. Estudo farmacognóstico do guaco Mikania glomerata Sprengel - Composta. Revista da Flora Medicinal, Rio de Janeiro, v. 9, n. 3, p. 101-132, 1942.

MAGALHÃES, P.M. O caminho medicinal das plantas: aspectos sobre o cultivo. Campinas: CPQBA/UNICAMP, 1997. 120 p.

MONTANARI JR., I. Aspectos do cultivo comercial de guaco (Mikania glomerata Sprengel e Mikania laevigata Schultz Bip ex Baker). Boletim Agroecológico, Botucatu, n. 11, p. 19, 1999. OLIVEIRA, F. Biofarmacognosia das espécies brasileiras da secção Globosae Robinson do gênero Mikania Willdenow. São Paulo, 1983. (Tese livre docência). Faculdade de Ciências Farmacêuticas, USP. OLIVEIRA, F; ALVARENGA, M.A.; AKISUE, G.; AKISUE, M.K. Isolamento e identificação de componentes químicos de Mikania glomerata Sprengel e de Mikania laevigata Schultz Bip. ex Baker. Revista de Farmácia e Bioquímica da Universidade de São Paulo, São Paulo, v. 20, n. 2, p. 169-183, 1984. RITTER, M.R.; BAPTISTA, L.R.M.; MATZENBACHER, N.I. Asteraceae. Gênero Mikania Willd. Secções Globosae e Thyrsigerae. Flora Ilustrada do Rio Grande do Sul, n. 21. Boletim do Instituto de Biociências, Porto Alegre, n. 50, p. 1-90, 1992.

SCHMITZ, J.A.K.; SOUZA, P.V.D.; KÄMPF, A.N. Características físicas de componentes de substratos de origem mineral e orgânica e suas misturas. In: ENCONTRO NACIONAL SOBRE SUBSTRATO PARA PLANTAS, 1., 1999, Porto Alegre. Resumos... Porto Alegre: UFRGS/ SEBRAE/AFLORI, 1999. p. 27-28.

SCHNEIDER, F.; KÄMPF, A.N. Efeito de substratos na produção em plugs de Limonium latifolium. In: ENCONTRO NACIONAL SOBRE SUBSTRATO PARA PLANTAS, 1., 1999, Porto Alegre. Resumos... Porto Alegre: UFRGS/ SEBRAE/AFLORI, 1999. p. 53-54.

SILVA, R.A.D. Pharmacopeia dos Estados Unidos do Brasil. São Paulo: Companhia Editora Nacional, 1929, p. 237.

SIMEPAR. Dados diários de temperatura. Estação 25254905, Pinhais. Curitiba: Sistema Meteorológico do Paraná. 1999.

SIMEPAR. Dados diários de temperatura. Estação 25254905, Pinhais. Curitiba: Sistema Meteorológico do Paraná. 2000.

SIMÕES, C.M.O.; MENTZ, L.A.; SCHENKEL, E.P.; IRGANG, B.E.; STEHMANN, J.R. Plantas da medicina popular no Rio Grande do Sul. 4. ed. Porto Alegre: UFRGS. 1995. 173 p. 